\title{
Highly efficient method for gene delivery into mouse dorsal root ganglia neurons
}

\section{Lingli Yu ${ }^{1,2,3}$, Florie Reynaud ${ }^{4}$, Julien Falk ${ }^{4}$, Ambre Spencer ${ }^{1,2,3}$, Yin-Di Ding 1,2,3, Véronique Baumlé ${ }^{1,3}$, Ruisheng Lu ${ }^{2,3}$, Valérie Castellani ${ }^{4}$, Chonggang Yuan ${ }^{1,3 *}$ and Brian B. Rudkin ${ }^{2,3 *}$}

\author{
Differentiation and Cell Cycle Group, Laboratoire de Biologie Moléculaire de la Cellule, UMR 5239, Centre National de la Recherche Scientifique, Ecole normale \\ Supérieure de Lyon, University of Lyon 1 Claude Bernard, University of Lyon, Lyon, France \\ ${ }^{2}$ Laboratory of Molecular and Cellular Neurophysiology, East China Normal University, Shanghai, China \\ 3 Joint Laboratory of Neuropathogenesis, Key Laboratory of Brain Functional Genomics, Chinese Ministry of Education, East China Normal University, Centre \\ National de la Recherche Scientifique, Ecole Normale Supérieure de Lyon, Shanghai, China \\ ${ }^{4}$ Centre de Génétique et Physiologie Moléculaire et Cellulaire, UMR Centre National de la Recherche Scientifique 5534, University of Lyon 1 Claude Bernard, \\ University of Lyon, Villeurbanne, France
}

\section{Edited by:}

Nicola Maggio, The Chaim Sheba

Medical Center, Israel

\section{Reviewed by:}

Daniele Bottai, University of Milan, Italy

Eldi Schonfeld-Dado, Stanford

University, USA

*Correspondence:

Brian B. Rudkin, Laboratoire de Biologie Moléculaire de la Cellule, UMR 5239 Centre National de la Recherche Scientifique, Ecole Normale Supérieure de Lyon, 46, allée d'Italie, 69364 Lyon, France e-mail: bbrudkin@ens-lyon.fr; Chonggang Yuan, Laboratory of Molecular and Cellular

Neurophysiology, East China Normal University, 3663 North Zhongshan Road, Shanghai 200062, China e-mail:cgyuan@bio.ecnu.edu.cn,
The development of gene transfection technologies has greatly advanced our understanding of life sciences. While use of viral vectors has clear efficacy, it requires specific expertise and biological containment conditions. Electroporation has become an effective and commonly used method for introducing DNA into neurons and in intact brain tissue. The present study describes the use of the Neon ${ }^{\circledR}$ electroporation system to transfect genes into dorsal root ganglia neurons isolated from embryonic mouse Day 13.5-16. This cell type has been particularly recalcitrant and refractory to physical or chemical methods for introduction of DNA. By optimizing the culture condition and parameters including voltage and duration for this specific electroporation system, high efficiency $(60-80 \%$ ) and low toxicity (>60\% survival) were achieved with robust differentiation in response to Nerve growth factor (NGF). Moreover, 3-50 times fewer cells are needed $\left(6 \times 10^{4}\right)$ compared with other traditional electroporation methods. This approach underlines the efficacy of this type of electroporation, particularly when only limited amount of cells can be obtained, and is expected to greatly facilitate the study of gene function in dorsal root ganglia neuron cultures.

Keywords: dorsal root ganglion (DRG) neuron, transfection, electroporation, nucleofection, gene expression, primary neurons, EGFP expression, Nerve growth factor (NGF)

\section{INTRODUCTION}

Culture of primary cells has been extensively used to study neuronal survival, signal transduction, development, and neurite outgrowth. Gene transfer, through both viral and non-viral methods, has become a powerful technique to assess the effects of expression of selected genes. Adenovirus, herpes-simplex virus (HSV), lentivirus, and adeno-associated virus (AAV) have been reported to deliver transgenes both in vivo and in vitro (Glatzel et al., 2000; Chattopadhyay et al., 2005; Towne et al., 2009; Yu et al., 2011). While effective, these approaches are timeconsuming, labor-intensive and carry some potential biohazard risk. Non-viral methods, which mainly include microinjection of DNA, biolistic, sonoporation, lipid- or chemical-based transfer or electroporation, offer faster and safer means for gene delivery (Table 1).

Electroporation, particularly because of its ease of use, combined with efficient and precise targeting in space and time, has become an effective method for introducing DNA into neurons in culture, slices and in intact neural tissue of Xenopus, chick and mouse (Kawabata et al., 2004; Falk et al., 2007; Saijilafu and Zhou, 2011). Dorsal root ganglia (DRG)-derived sensory neurons that are selectively sensitive to Nerve growth factor (NGF), Brain derived neurotrophic factor (BDNF) and Neurotrophin-3 (NT3), provide an excellent model in which to study the mechanisms of axonal regeneration, neurotrophin signaling, peripheral nervous system development and peripheral neuron disease (Melli and Hoke, 2009; Newbern et al., 2011). Existing electroporation methods of dissociated DRG neurons require relatively large amounts of cells. As example, the Amaxa Nucleofector system, one of the best known and commonly performed transfection methods now in the labs, requires $1 \times 10^{6} \mathrm{DRG}$ cells in $100 \mu \mathrm{l}$ for each electroporation [e.g., Chick DRG (Chadborn et al., 2006); Manufacturer's instructions]. This is a major obstacle when working with embryos. Additionally, the low survival and transfection rate with the standard Amaxa system are of major concern. Though encouraging results have been reported recently with adult Rat DRG using the 4D-Nucleofector system-X from Lonza (McCall et al., 2012), electroporation of dissociated DRG neurons, from young mouse embryos, whose cell number is limiting, remains a challenge.

Herein, we describe an optimized procedure for isolation and dissociation of mouse embryonic DRG neurons and their electroporation with plasmid DNA $(\approx 5 \mathrm{~kb}$ and $\approx 4.7 \mathrm{~kb})$ in a rapid and highly effective manner with efficiencies comparable to those reported for viral infection, while maintaining high viability and transgene expression. 
Table 1 | Comparison of non-viral methods commonly used to transfect mammalian neurons.

\begin{tabular}{|c|c|c|c|c|c|c|}
\hline \multirow[t]{2}{*}{ Non-viral method } & \multicolumn{2}{|c|}{ Model } & \multicolumn{2}{|c|}{ Maximal efficiency } & \multirow{2}{*}{$\begin{array}{l}\text { Cell } \\
\text { survival }\end{array}$} & \multirow[t]{2}{*}{ References } \\
\hline & Precursors & $\begin{array}{l}\text { Post-mitotic } \\
\text { cells }\end{array}$ & DNA plasmids & RNAi & & \\
\hline $\begin{array}{l}\mathrm{Ca}^{2+} \text { phosphate/DNA } \\
\text { co-precipitation }\end{array}$ & & $\mathrm{erHCn}$ & $\begin{array}{l}\text { Typically between } 1 \text { and } 5 \% \text {; } \\
12 \text { and } 27 \% \text { under highly } \\
\text { controlled conditions }\end{array}$ & Efficient\%n.c. & \%n.c. & Goetze et al., 2004 \\
\hline \multirow[t]{2}{*}{ Lipofection } & & $\begin{array}{c}\mathrm{nmCGn} \\
\text { erHCn/erCn }\end{array}$ & $\begin{array}{l}\text { Effective ( } \geq 50 \% \text { Knock-down) } \\
20-25 \% / 25-30 \%^{a}\end{array}$ & $\begin{array}{l}\% \text { n.c. } \\
-\end{array}$ & $\begin{array}{l}\% \text { n.c. } \\
100 \%{ }^{b}\end{array}$ & $\begin{array}{l}\text { Butcher et al., } 2009 \\
\text { Ohki et al., 2001; Dalby et al., } \\
2004\end{array}$ \\
\hline & & $\mathrm{erHCn}$ & - & $73 \%^{c}$ & $89-96 \%$ & Tonges et al., 2006 \\
\hline Biolistics & & & $\begin{array}{l}\text { Typically around } 2 \% \text {, rarely } \\
\text { reaches } 10 \% \text { in cultured } \\
\text { neurons, up to } 34 \% \text { in slice } \\
\text { culture }\end{array}$ & - & $\%$ n.c. & Karra and Dahm, 2010 \\
\hline Sonoporation & & DRGn & $31 \%$ & & $35 \%$ & Lin et al., 2010 \\
\hline \multirow[t]{5}{*}{$\begin{array}{l}\text { Electroporation } \\
\text { "Nucleofection" }\end{array}$} & & $\begin{array}{c}\text { nr/ar/amDRGn/ } \\
\text { SCGn }\end{array}$ & $5-20 \%$ & Efficient & $\%$ n.c. & Dib-Hajj et al., 2009 \\
\hline & & ecDRGn & & & $37 \%$ & Martinez and Hollenbeck, 2003 \\
\hline & $\mathrm{mNSC}$ & & $88 \%$ & Efficient $>50 \%$ & $78 \%$ & Bertram et al., 2012 ${ }^{d}$ \\
\hline & hNPCs & & $10-20 \%$ & & $44 \%$ & Dieterlen et al., 2009 \\
\hline & & $\begin{array}{c}\operatorname{arDRGn/} \\
\text { erDRGn/ } \\
\text { ecDRGn/SCGn/ } \\
\text { erHCn }\end{array}$ & $39-42 \%$ & & $\%$ n.c. & $\begin{array}{l}\text { Chadborn et al., 2006; Jones } \\
\text { et al., 2006; MacGillavry et al., } \\
\text { 2009; Ketschek and Gallo, } \\
\text { 2010; McCall et al., 2012; } \\
\text { Pristera et al., 2012; Kirton } \\
\text { et al., } 2013\end{array}$ \\
\hline
\end{tabular}

erHCn, embryonic rat hippocampal neurons; hNPCs, human neural progenitor cells; NSC, neural stem cells; CGns, cerebellar granule neurons; SCGn, superior cervical ganglion neurons. amDRGn, adult Mouse DRGn; emDRGn, embryonic mouse DRGn; arDRGn, adult Rat DRGn; nrDRGn, neonatal rat DRGn; ecDRGn, embryonic chick DRGn; \%n.c., percent not communicated.

a Lipofectamine $2000^{\text {TM }}$.

${ }^{b}$ The authors state that $100 \%$ of the cells in transfected cultures are viable.

c Stearyl-R8.

${ }^{d}$ Nucleofector $^{\circledR} 4 D$.

\section{MATERIALS AND METHODS}

REAGENTS

Poly-L-Lysine (P1399, Sigma-Aldrich), Laminin (L2020, SigmaAldrich), calcium/magnesium free Hank's Balanced Salt Solution (HBSS) (14170, Life technologies), Trypsin (T5266, SigmaAldrich, $\mathrm{pH}=7.2$ ), DNAse I (DN25, Sigma-Aldrich), Nutrient Mixture F-12 (21765, Life technologies), Fetal calf serum (FCS) (10270106, Life technologies), penicillin-streptomycin (P/S) (15140, Life technologies), Nerve growth factor (NGF) (mouse 2.5S; N-100, Alomone Labs), Cytosine-arabinoside "AraC” (C1768, Sigma-Aldrich), anti-ßIII tubulin antibody (SC53140, Santa Cruz), Donkey anti-mouse antibodies conjugated to Alexa Fluor ${ }^{\circledR} 488$ (715-545-151, Jackson ImmunoResearch), Vectashield (Vector, H-1000).

\section{ANIMALS}

Time pregnant OF1 mice were purchased from Charles River (France). The mice were euthanized by cervical dislocation according to ethical committee recommendations (Authorization \# 007050).

\section{PLASMIDS}

pEGFP-N1 (4.7 kb) was from Lonza; pCDNA3.1-Cav-1 fused to RFP (pCDNA3.1-Cav-1-RFP (5.25 kb), Addgene Plasmid 14434) was a gift from R. E Pagano; (Sharma et al., 2004); pCDNA3.1RFP was modified by removing the Cav1 coding sequence from pCDNA3.1-Cav-1-RFP. An Endofree DNA purification kit (Nucleobond XtraMAxi, ref. 740424.10) was used to isolate GFP, RFP and CAV1-RFP plasmids according to manufacturer's 
protocol. Plasmids were resuspended in culture grade $\mathrm{PBS}\left(\mathrm{Ca}^{++}\right.$, $\mathrm{Mg}^{++}$-free; 14190-094, Life technologies) at 3-5 $\mu \mathrm{g} / \mu \mathrm{l}$.

\section{PREPARATION OF COATED COVERSLIPS}

Coverslips were soaked in $96 \%$ ethanol for $30 \mathrm{~min}$, then washed with distilled water and/or air dried. Poly-L-lysine $(50 \mu \mathrm{g} / \mathrm{ml})$ was spread equally over the surface of the coverslip, followed by incubation for $3 \mathrm{~h}$ at room temperature or overnight at $4^{\circ} \mathrm{C}$. They were subsequently rinsed with distilled water, then $50 \mu l$ Laminin $(10 \mu \mathrm{g} / \mu \mathrm{l})$ in HBSS was applied on a coverslip. A second coverslip was placed, coated side down, on the first one, then allowed to sit overnight at $37^{\circ} \mathrm{C}$. After two washes with HBSS, the coverslips were placed one per well into a 24 -well tissue culture plate. Wells were then filled with $500 \mu \mathrm{l}$ of culture medium without antibiotics and plates pre-incubated in a humidified $37^{\circ} \mathrm{C} / 5 \% \mathrm{CO}_{2}$ incubator prior to use.

\section{ISOLATION AND DISSOCIATION OF DORSAL ROOT GANGLIA FROM MOUSE EMBRYOS}

We used a modified protocol, adapted from a previously described procedure for isolation and culture of cortical neurons (Castellani et al., 2004; Falk et al., 2014). Time pregnant mice at E14.5 were sacrificed by cervical dislocation and embryos were removed from the uterus kept on ice. Heads were removed from the embryos in ice cold HBSS $\left(\mathrm{Ca}^{++} / \mathrm{Mg}^{++}\right.$-free) and the bodies washed in the same. Both Male and Female embryos were used. The embryos were pinned down on the silicon-coated dish with dorsal side up in cold HBSS with $2 \%$ glucose. The skin of the embryo was cut along the dorsal midline. The cartilage was then cut along the midline and the spinal cord removed with the forceps tip by sliding them along the spinal cord. The meninge was removed to visualize the DRG along the vertebral canal, which were taken out one by one using forceps. Buffer in the dissection dish was changed for every embryo. Typically up to 18 DRG are isolated per embryo.

Dissected DRG from three E14.5 embryos were transferred into an eppendorf tube containing $270 \mu \mathrm{l}$ of ice cold in $\mathrm{Ca}^{++} / \mathrm{Mg}^{++}$-free HBSS to which $30 \mu \mathrm{l}$ of trypsin $(25 \mathrm{mg} / \mathrm{ml})$ were added to yield a final concentration of $\approx 2.5 \mathrm{mg} / \mathrm{ml}$ (Total volume $\approx 300 \mu \mathrm{l}$ ) and incubated for $10 \mathrm{~min}$ at $37^{\circ} \mathrm{C} .10 \mu \mathrm{l}$ of DNAse I $(0.1 \mathrm{mg} / \mathrm{ml})$ were added to a final concentration of $0.033 \mathrm{mg} / \mathrm{ml}$, and returned to $37^{\circ} \mathrm{C}$ for an additional $10 \mathrm{~min}$ incubation, gently shaking the tube approximately every $3 \mathrm{~min}$ to equally distribute the DRG. Neutralization of the trypsin was performed by adding $30 \mu \mathrm{l}$ of FBS followed by $500 \mu \mathrm{l}$ of culture medium (F12, 10\% FBS without antibiotics). DRG explants were centrifuged $3 \mathrm{~min}$ at $900 \mathrm{rpm}$ (fixed angle rotor, radius $60 \mathrm{~mm}$, Eppendorf minispin) and Trypsin-containing medium was removed. Mechanical dissociation of cells was carried out using a fire polished glass Pasteur pipette with a bulb, by triturating approximately 15 times in $200 \mu \mathrm{F} 12,10 \%$ FCS without antibiotics. Cells were counted to evaluate the number of conditions possible $\left(6-9 \times 10^{4}\right.$ cells per condition) before resuspension in electroporation buffer. An average of $27 \times 10^{4}$ cells were isolated per embryo (range $18-37 \times 10^{4}$ ).

In order to achieve a high survival rate of the cells, it is essential to keep the dissection within $1 \mathrm{~h}$ after sacrifice of the mother.

\section{ELECTROPORATION}

After counting the cells, $1.3 \mathrm{ml} \mathrm{Ca}{ }^{++} / \mathrm{Mg}^{++}$-free HBSS was added and the cells centrifuged for $2 \mathrm{~min}$ at $300 \mathrm{rpm}$ (fixed angle rotor, radius $60 \mathrm{~mm}$, Eppendorf minispin). The cells were resuspended with half of the electroporation buffer R (Invitrogen) that would be needed for the number of conditions estimated. Since cells are lost in this process, they were counted again to adjust the amount to $6-9 \times 10^{4}$ cells per condition with electroporation buffer $\mathrm{R}$ $(10 \mu \mathrm{l}$ total per electroporation). $10 \mu \mathrm{l}$ of cells were gently pipetted into each microfuge tube, then mixed with the appropriate plasmids, i.e., pEGFP (Lonza) $(0.5 \mu \mathrm{g})$ and pCDNA3.1-Cav-1 fused to RFP (pCDNA3.1-Cav-1-RFP) or pCDNA3.1-RFP (1 or $2 \mu \mathrm{g})$. Cells were immediately electroporated using the Neon ${ }^{\oplus}$ transfection system. Electrical parameters, i.e., voltage and pulse length, were varied in order to find the optimal conditions. Cells should not be kept in the electroporation buffer for longer than $10 \mathrm{~min}$. After electroporation, cells were immediately transferred into two wells with coated coverslips, containing medium without antibiotics, pre-warmed to $37^{\circ} \mathrm{C}$. The culture dishes were gently rocked to ensure even distribution of the cells, which were then left to settle for $1 \mathrm{~h}$ in the $\mathrm{CO}_{2}$ incubator at $37^{\circ} \mathrm{C}$. NGF ( $50 \mathrm{ng} / \mathrm{ml}$ final) and antibiotics ( $1 \%$ final) were then added to the medium and $12 \mathrm{~h}$ later, Ara-C ( $10 \mu \mathrm{M}$ final $)$ was added to remove contaminating glial cells.

\section{IMAGING AND DATA ANALYSIS}

Control and caveolin-1-RFP-expressing cultures from the same dissociation batch were fixed in $2 \%$ paraformaldehyde for $14-16 \mathrm{~h}$ at $4^{\circ} \mathrm{C}, 24$ and $48 \mathrm{~h}$ after addition of NGF, and transgene expression was analyzed. Phase contrast and fluoresence images were acquired using a 20x objective as a $3 \times 3$ montage. 4 montages of 9 images were collected in different regions of the coverslips to minimize bias due to different cell density (Zeiss AxioImager, $\mathrm{Z} 1$ upright). The number of transfected neurons per image was calculated using the Cell Counter plugin for ImageJ.

For determination of the impact of electroporation on cell survival and differentiation, non-transfected control and $1 \mu \mathrm{g}$ RFP/0.5 $\mu \mathrm{g}$ GFP expressing cultures from the same dissociation batch were fixed in $2 \%$ paraformaldehyde for $14-16 \mathrm{~h}$ at $4^{\circ} \mathrm{C}$, 24 and $48 \mathrm{~h}$ after addition of NGF. Phase contrast images were acquired using a Zeiss AxioImager, Z1 upright, 20x objective. Approximately 14 images were collected in different regions of the coverslips to minimize bias due to different cell density. The number of surviving neurons (round, bright clear) per image was

Table 2 | Optimization of electroporation.

\begin{tabular}{lcc}
\hline Conditions & Survival & Efficiency \\
\hline 1. 1500 V 20 ms 1 pulse & ++ & + \\
2. 1600 V 10 ms 3 pulses & + & ++ \\
3. 1300 V 20 ms 2 pulses & ++ & ++ \\
\hline
\end{tabular}

DRG neurons (6-9 $\times 10^{4}$ cells for each condition) were electroporated with pEGFP $(1 \mu \mathrm{g}$, Lonza). Electroporation conditions were optimized for voltage, duration and number of pulses. After $24 \mathrm{~h}$, cell viability and transfection efficiency were assessed by visual inspection. 
calculated using the Cell Counter plugin for ImageJ. The overall neurite outgrowth per image was calculated using the NeuronJ plugin for ImageJ ( 1 pixel $=0.318 \mu \mathrm{m})$.

For immunolabeling of neurons, cells were fixed in $2 \%$ paraformaldehyde for $14-16 \mathrm{~h}$ at $4^{\circ} \mathrm{C}$ and permeabilized at room temperature (RT) for $5 \mathrm{~min}$ with $0.1 \%$ Triton $\mathrm{X}-100$ in PBS. After washing with PBS at RT, cells were blocked for $1 \mathrm{~h}$ at RT with $10 \%$ normal goat serum/1\% BSA $/ 0.1 \%$ Triton in PBS. Samples were incubated with anti- $\beta$ III tubulin mouse monoclonal antibody (Santa Cruz, SC-53140) 14$16 \mathrm{~h}$ at $4^{\circ} \mathrm{C}$ and visualized with secondary antibodies conjugated to Alexa 488 (Goat-anti-mouse, Jackson ImmunoResearch, 115-485-003) to label neurons. Coverslips were mounted in
Vectashield. Images were acquired using Olympus FluoView FV10i. Data acquisition was performed with Olympus FluoView software.

\section{STATISTICS}

Statistical significance between various groups was tested using the Mann-Whitney test.

\section{RESULTS \\ OPTIMIZATION OF TRANSFECTION CONDITIONS FOR DISSOCIATED DRG NEURONS}

To determine the protocol that would produce the highest possible transfection efficiency and greatest survival, the DRG neurons

Table 3 | Percentage of RFP and Cav1-RFP positive cells with different expression constructs.

\begin{tabular}{|c|c|c|c|c|}
\hline Time point & Construct & $\begin{array}{c}\text { Percentage of GFP(+) } \\
\text { neurons/Total neurons }(\%)\end{array}$ & $\begin{array}{c}\text { Percentage of } \operatorname{RFP}(+) \\
\text { neurons/total neurons }(\%)\end{array}$ & $\begin{array}{l}\text { Percentage of Cav1-RFP(+) } \\
\text { neurons/Total neurons (\%) }\end{array}$ \\
\hline \multirow[t]{4}{*}{$24 \mathrm{~h}$} & $0.5 \mu \mathrm{g}$ GFP/1 $\mu \mathrm{g}$ RFP & $58.1 \pm 3.7$ & $57.9 \pm 3.6$ & \\
\hline & $0.5 \mu \mathrm{g}$ GFP/1 $\mu \mathrm{g}$ Cav1-RFP & $51.5 \pm 2.0$ & & $53.9 \pm 1.7$ \\
\hline & $0.5 \mu \mathrm{g}$ GFP/2 $\mu \mathrm{g}$ RFP & $55.0 \pm 3.1$ & $55.2 \pm 3.1$ & \\
\hline & $0.5 \mu \mathrm{g}$ GFP/2 $\mu \mathrm{g}$ Cav1-RFP & $50.5 \pm 3.1$ & & $52.6 \pm 3.6$ \\
\hline \multirow[t]{4}{*}{$48 \mathrm{~h}$} & $0.5 \mu \mathrm{g}$ GFP/1 $\mu \mathrm{g}$ RFP & $62.6 \pm 2.5$ & $62.6 \pm 2.5$ & \\
\hline & $0.5 \mu \mathrm{g}$ GFP/1 $\mu \mathrm{g}$ Cav1-RFP & $67.0 \pm 3.7$ & & $80.3 \pm 2.8$ \\
\hline & $0.5 \mu \mathrm{g}$ GFP/2 $\mu \mathrm{g}$ RFP & $68.6 \pm 3.3$ & $68.0 \pm 3.1$ & \\
\hline & $0.5 \mu \mathrm{g}$ GFP/2 $\mu \mathrm{g}$ Cav1-RFP & $60.1 \pm 5.2$ & & $64.5 \pm 4.8$ \\
\hline
\end{tabular}

Cells were transfected with pEGFP and each expression construct for RFP at two different concentrations and the number of transfected cells was determined by visual inspection. Results were obtained from three independent experiments. Data represent Mean \pm S.E.M.

A
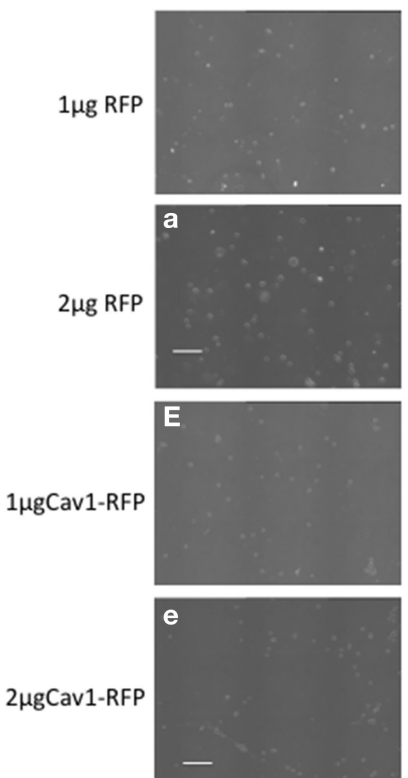

B
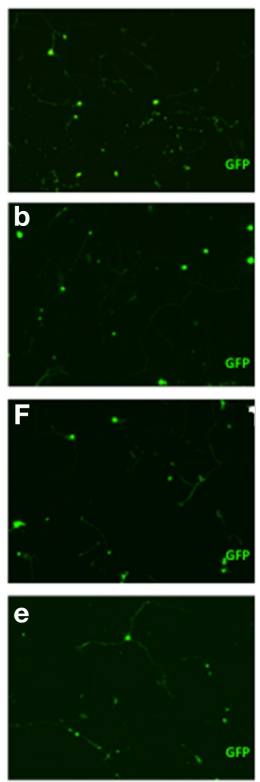

C
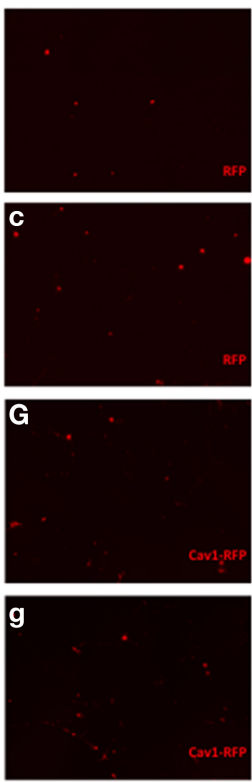

D
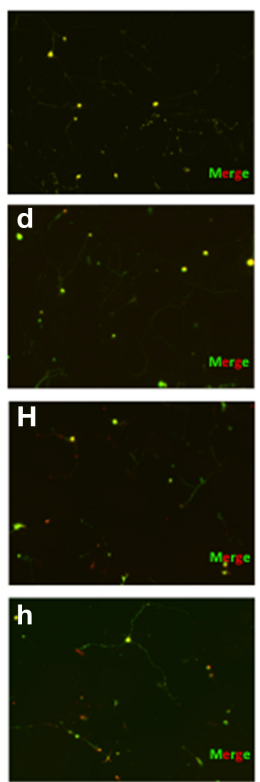

FIGURE 1 | Expression of fluorescent proteins in DRG neurons. Neon transfection leads to efficient electroporation of E14.5 DRG neurons. Neurons were transfected with $0.5 \mu \mathrm{g}$ EGFP along with 1 or $2 \mu \mathrm{g}$ of RFP or 1 or $2 \mu \mathrm{g}$ Cav1-RFP. $24 \mathrm{~h}$ after electroporation, cells were fixed and observed under the microscope. Column A: Phase contrast image. Column B: GFP fluorescence. Column C: RFP fluorescence. Column D: Merge of GFP and RFP Fluorescence. Scale Bars represent $200 \mu \mathrm{m}$. 
were electroporated with $1 \mu \mathrm{g}$ pEGFP, varying voltage, duration and number of pulses. The three pulse parameters listed in Table 2 were initially tested in this work since they have been successfully applied to hippocampal, cortical and neuronal stem cells from rat embryos (Manufacturer's protocol). After $24 \mathrm{~h}$, cell viability and transfection efficiency were assessed by visual inspection. As shown in Table 2, electroporation with two pulses at $1300 \mathrm{~V}$ with a pulse width of $20 \mathrm{~ms}$, produced high transfection efficiencies and cell viability. Therefore, this setting was utilized for subsequent experiments.

The amount of pCDNA3.1-Cav-1-RFP or pCDNA3.1-RFP DNA was then varied between 1 and $2 \mu \mathrm{g}$ for which the volume was normalized to $10 \%$ of the total reaction volume in distilled water; $0.5 \mu \mathrm{g}$ pEGFP was co-transfected for neurite tracing in transfected neurons. 24 and $48 \mathrm{~h}$ post-transfection, the cells were fixed and processed for microscopic analysis. As shown in Table 3, over $50 \%$ of the neurons were positive for GFP, while increasing RFP or Cav1-RFP plasmid concentration did not result in significantly higher transfection efficiency. On average, all conditions considered, a transfection efficiency of $54 \pm 1.1 \%$ (Average \pm S.E.M.) was achieved at $24 \mathrm{~h}$. After $48 \mathrm{~h}, 67 \pm 1.4 \%$ of fluorescent neurons were observed, indicating the survival of transfected neurons.

Essentially all of the cells carrying GFP were also transfected with RFP or Cav1-RFP (Figure 1). Both EGFP and RFP were visualized over the entire length of the axons, whereas Cav1-RPF was predominantly expressed in the cell body (Figure 2 ).

Other parameters, such as the cell density and plasmid purity are also important issues. Use of low cell numbers $2 \times 10^{4}$ to $4 \times 10^{4}$ cells/electroporation, resulted in decreased transfection efficiency (Not shown). Also, avoiding multiple centrifugations during the procedure effectively reduces cell loss while enhancing viability. The use of endo-free plasmids is highly recommended as they result in high cell viability and thereby complement the transfection efficiency.

Finally, as mentioned in the Materials and Methods section, it is particularly important for the high transfection efficiency and survival to use DRG isolated within $1 \mathrm{~h}$ after sacrifice of the mother.

\section{THE SURVIVAL AND DIFFERENTIATION OF DRG NEURONS AFTER ELECTROPORATION}

Since high electroporation efficiencies are often achieved at the expense of cell survival, we evaluated survival subsequent to Neon ${ }^{\circledR}$ electroporation. Under phase-contrast, healthy neuronal cells are easily distinguished since their cell bodies are round and phase bright and display extensive neurite outgrowth, as shown in Figure 3. As shown in Figure 4A, cultures of transfected neurons had approximately 35\% fewer neurons than cultures of non-transfected neurons. Between 24 and $48 \mathrm{~h}$, neuron number was maintained, under both conditions, indicating that the transfected neurons survived as well as non-transfected. 24 and $48 \mathrm{~h}$ post-electroporation, neuronal survival rates were $65 \%$ of naïve, non-transfected controls.

The extent of average neurite growth was as robust in transfected cultures as with non-transfected, increasing in both between 24 and $48 \mathrm{~h}$ (Figure 4B). The average neurite length in non-transfected cultures at $24 \mathrm{~h}$ was $885 \pm 93$ pixels per neuron vs. $892 \pm 90$ for transfected. At $48 \mathrm{~h}$, average neurite length was $1077 \pm 71$ pixels/neuron in non-transfected and $1302 \pm 95$ in transfected cultures.

\section{DISCUSSION}

Electroporation, because of its ease of use, reproducibility and relatively high efficiency, has been developed and widely used for introducing various molecules into cells. In this study, we
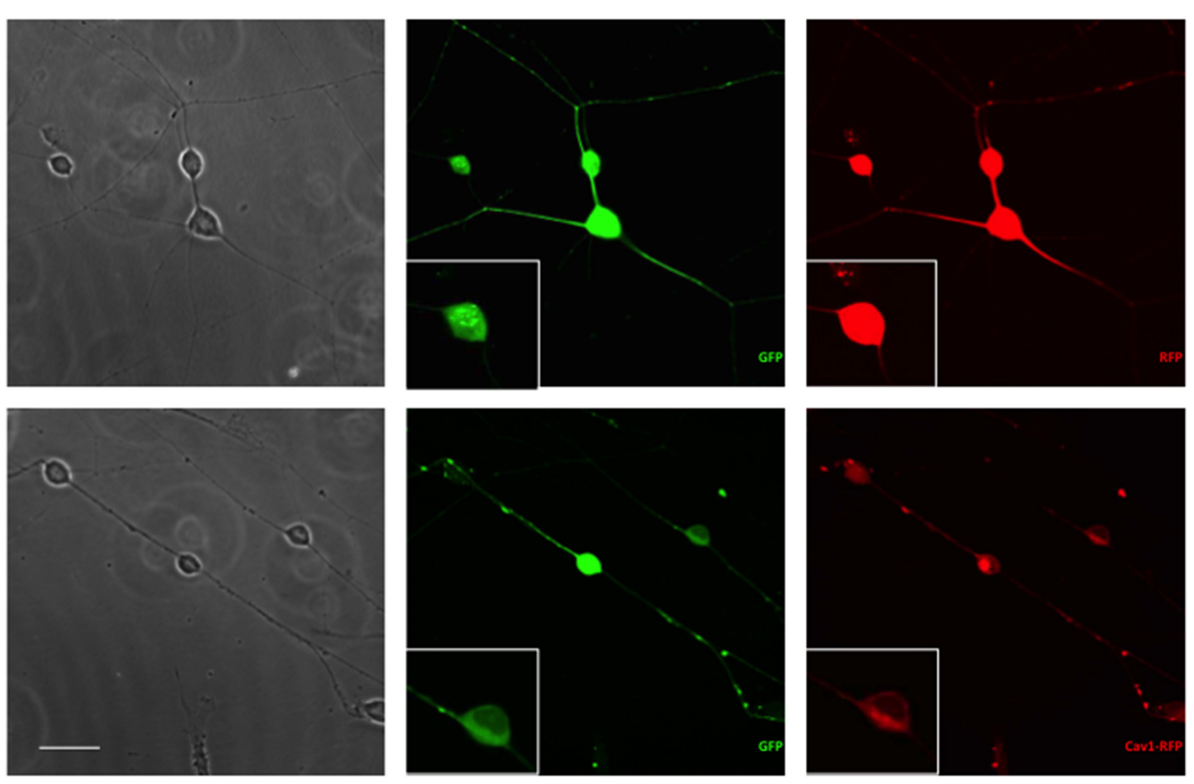

FIGURE 2 | Expression of fluorescent proteins in DRG neurons. Neurons were transfected with $1 \mu \mathrm{g}$ RFP or Cav1-RFP combined with $0.5 \mu \mathrm{g}$ EGFP. $24 \mathrm{~h}$ after electroporation, cells were fixed and observed under the microscope. Scale Bar represents $50 \mu \mathrm{m}$. 

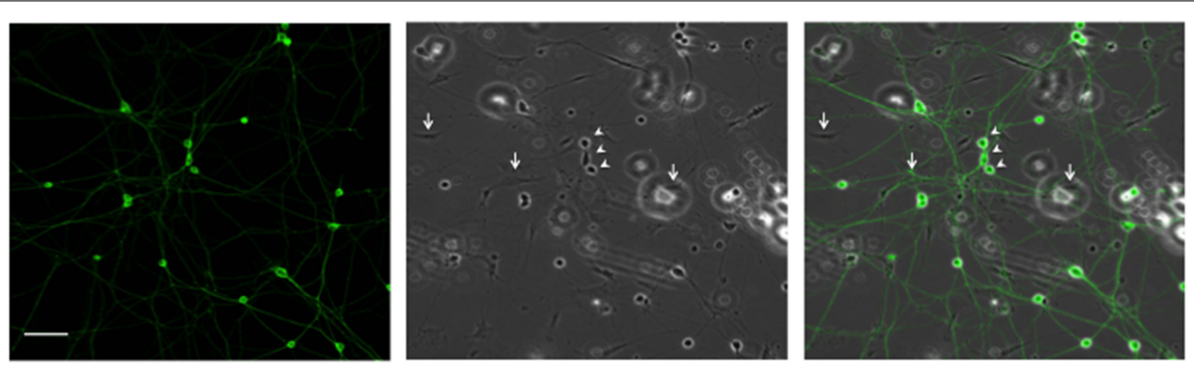

FIGURE 3 | Representative DRG neurons in culture. DRG neurons were dissected and maintained in culture. $24 \mathrm{~h}$ later, cells were fixed and labeled with anti- $\beta$ III tubulin antibody. Arrows and arrowheads point, respectively, to glial and neuronal cells. Scale Bar represents $100 \mu \mathrm{m}$.

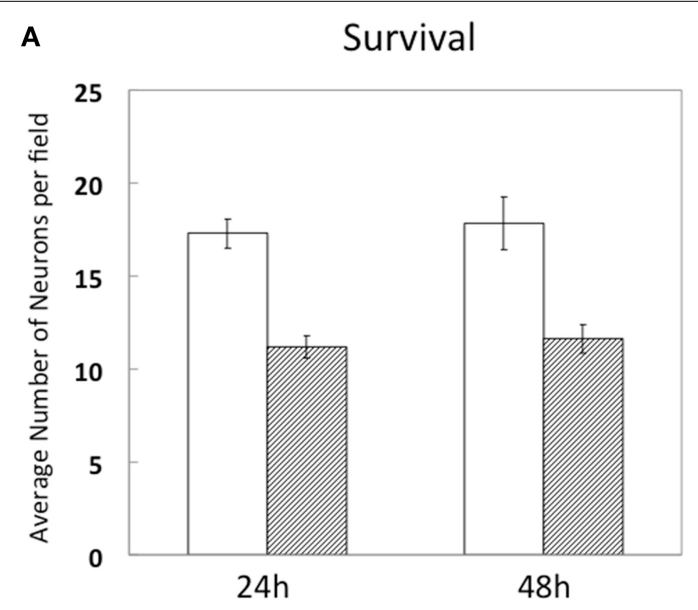

B

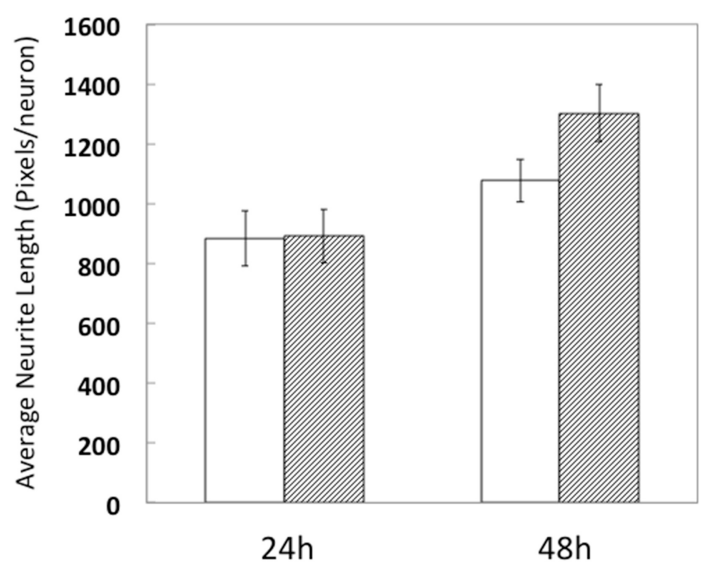

FIGURE 4 | Survival and differentiation of DRG neurons after electroporation. DRG neurons were prepared and directly cultured without transfection (white bars) or transfected with $1 \mu \mathrm{g}$ RFP combined with $0.5 \mu \mathrm{g}$ EGFP (hashed bars). 24 and $48 \mathrm{~h}$ after electroporation, cells were fixed and neuron survival (A) and average neurite length per neuron (1pixel $=0.318 \mu \mathrm{m})(\mathbf{B})$ were calculated compared to naïve, non-transfected neurons. Results were obtained from three independent experiments. Data represent mean \pm S.E.M. derived from 40 images representative of 692 non-transfected neurons $(24 \mathrm{~h})$ and 39 images representative of 439 GFP/RFP expressing neurons and 29 images representative of 523 non-transfected neurons and 31 images representative of 360 GFP/RFP expressing neurons of naïve, non-transfected controls (48 h). describe an optimized method for gene delivery into embryonic DRG neurons, with high transfection efficiency of $>60 \%$, and low cytotoxicity as reflected in a $2 / 3$ survival rate and robust differentiation, comparable to non-transfected cultures.

Primary neurons present a particular challenge to successful gene transfer. Adenovirus (Ad), adenovirus-associated virus (AAV) was successfully used for gene transfer via in vivo injection of mice (Glatzel et al., 2000). Herpes simplex virus (HSV) (Storey et al., 2002), and lentivirus (Yu et al., 2011) have been applied in rat DRG cells. Although they effectively deliver genes into DRG cells, several viruses can affect sensory neuron physiology (Fukuda and Kurata, 1981; Maehlen et al., 1991; Farkas et al., 1994) and thus limit their use in some experiments.

The Neon ${ }^{\circledast}$ transfection system applied to embryonic DRG neurons as described herein, resulted in a mean transfection efficiency for DNA plasmids well over 60\% in DRG neurons, along with high viability and robust differentiation comparable to non-transfected cultures at $48 \mathrm{~h}$ which, to our knowledge, is the highest reported for a non-viral transfection method, yielding levels comparable to viral infection (Table 4).

Usually, $1-2 \times 10^{6}$ cells are required for each electroporation to achieve reasonable number of transfectants and good cell survival in the first and second generation electroporation apparatuses. This is due to the necessity to have an optimal cell density and the original large volume $(100 \mu \mathrm{l})$ of the electroporation chambers. The advent of smaller chamber volumes allows a significant reduction in cell number. As few as $3 \times 10^{5}$ cells have been successfully used with the Nucleofector $4 \mathrm{D}$ in a volume of $20 \mu \mathrm{l} / 1 \mathrm{~mm}$ chamber with an efficiency of $40 \%$, which is comparable to the results obtained with the $100 \mu$ l chamber (Manufacturer's protocol) and survival rates of up to almost 30\% (McCall et al., 2012). The Neon ${ }^{\circledast}$ system was reported to have been successfully used DRG neurons isolated from adult Rats, with a cell number $\left(5 \times 10^{4}\right)$ and program similar to the one we have found to be optimal for DRG's isolated from embryonic mice. There is no data however on the actual efficiency or survival. Using the approach presented herein $6-9 \times 10^{4}$ cells were sufficient for each transfection of DRG neurons from mouse embryos. Thus, with the cells obtained, for example, from one E14.5 embryo, four electroporations can be performed, largely expanding the experimental conditions, while reducing the total number of embryos needed for certain types of experiments. The other main advantage of our method is that, when electroporated 


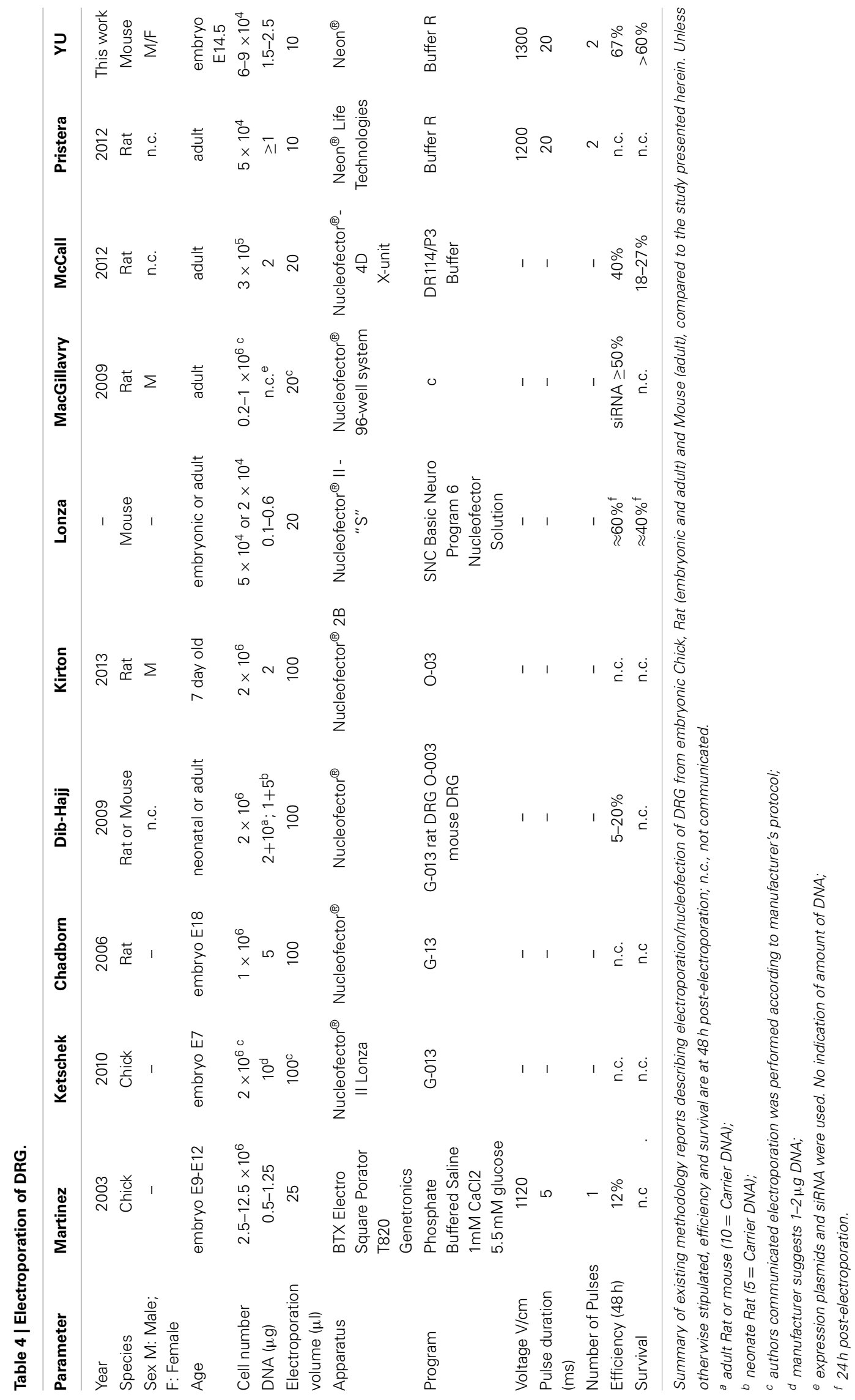


with mixed plasmids comprising EGFP and RFP at a ratio of $1: 2-1: 4$, we found that essentially all of the neurons expressed both of these fluorescent proteins. As EGFP was sufficiently detectable the entire length of the axons, one can easily analyze the effect of transfected genes with a GFP-based imaging system. By combining other plasmid constructs, such as TET-ON/OFF system (Shaikh and Nicholson, 2006) and using cell type-specific promoters (Hitoshi et al., 1999; Boulaire et al., 2009; Gulick and Robbins, 2009), it should be possible to express transgenes in a spatiotemporal manner. In summary, the transfection protocol presented herein for embryonic DRG neurons, employed the Neon $^{\circledR}$ transfection system and effectively enabled heterologous gene expression in DRG neurons.

While viral transduction/infection has yielded significant advances, it remains more labor-intensive than electroporation of purified plasmids. Furthermore, there are safety issues regarding the types of genes that can be introduced under standard laboratory conditions, e.g., oncogenes or genes that inhibit apoptosis or modulate autophagy. Clearly, implementation of the protocol proposed herein alleviates both issues, enabling investigation of the impact of such genes or modulators thereof on DRG survival, differentiation and function.

\section{AUTHOR CONTRIBUTIONS}

Lingli Yu, Florie Reynaud, Julien Falk, Chonggang Yuan, and Brian B. Rudkin - participated in the conception, execution and analysis of experiments and in the writing of the manuscript. Ambre Spencer, Yin-Di Ding, Véronique Baumlé, and Ruisheng $\mathrm{Lu}$ participated in the conception, execution and analysis of initial experiments. Valérie Castellani oversaw the experiments at CGphiMC, participated in the data analysis, revision and final approval of the text. All authors agree to be accountable for all aspects of the work.

\section{ACKNOWLEDGMENTS}

This work was supported by MIRA grants from the Rhone Alps Region of France, by the CNRS (International program for Scientific Cooperation, "PICS") to Brian B. Rudkin and from the East China Normal University to Chonggang Yuan. Personnel support Lingli Yu, Yin-Di Ding: Ministry of Education of China; Rhone Alps Region; East China Normal University; Ambre Spencer, Yin-Di Ding: Ministry of Foreign Affairs of France; Ambre Spencer: the Rhone Alps Region, CNRS, ARC (Association pour la Recherche contre le Cancer). Support of the PLATIM Microscopy platform of the US8/UMS3444 BioSciences Gerland-Lyon Sud is graciously acknowledged.

\section{REFERENCES}

Bertram, B., Wiese, S., and von Holst, A. (2012). High-efficiency transfection and survival rates of embryonic and adult mouse neural stem cells achieved by electroporation. J. Neurosci. Methods 209, 420-427. doi: 10.1016/j.jneumeth.2012.06.024

Boulaire, J., Balani, P., and Wang, S. (2009). Transcriptional targeting to brain cells: engineering cell type-specific promoter containing cassettes for enhanced transgene expression. Adv. Drug Deliv. Rev. 61, 589-602. doi: 10.1016/j.addr.2009.02.007

Butcher, A. J., Torrecilla, I., Young, K. W., Kong, K. C., Mistry, S. C., Bottrill, A. R., et al. (2009). N-methyl-D-aspartate receptors mediate the phosphorylation and desensitization of muscarinic receptors in cerebellar granule neurons. J. Biol. Chem. 284, 17147-17156. doi: 10.1074/jbc.M901031200
Castellani, V., Falk, J., and Rougon, G. (2004). Semaphorin3A-induced receptor endocytosis during axon guidance responses is mediated by L1 CAM. Mol. Cell. Neurosci. 26, 89-100. doi: 10.1016/j.mcn.2004.01.010

Chadborn, N. H., Ahmed, A. I., Holt, M. R., Prinjha, R., Dunn, G. A., Jones, G. E., et al. (2006). PTEN couples Sema3A signalling to growth cone collapse. J. Cell. Sci. 119, 951-957. doi: 10.1242/jcs.02801

Chattopadhyay, M., Krisky, D., Wolfe, D., Glorioso, J. C., Mata, M., and Fink, D. J. (2005). HSV-mediated gene transfer of vascular endothelial growth factor to dorsal root ganglia prevents diabetic neuropathy. Gene. Ther. 12, 1377-1384. doi: 10.1038/sj.gt.3302533

Dalby, B., Cates, S., Harris, A., Ohki, E. C., Tilkins, M. L., Price, P. J., et al. (2004). Advanced transfection with Lipofectamine 2000 reagent: primary neurons, siRNA, and high-throughput applications. Methods 33, 95-103. doi: 10.1016/j.ymeth.2003.11.023

Dib-Hajj, S. D., Choi, J. S., Macala, L. J., Tyrrell, L., Black, J. A., Cummins, T. R., et al. (2009). Transfection of rat or mouse neurons by biolistics or electroporation. Nat. Protoc. 4, 1118-1126. doi: 10.1038/nprot.2009.90

Dieterlen, M. T., Wegner, F., Schwarz, S. C., Milosevic, J., Schneider, B., Busch, M., et al. (2009). Non-viral gene transfer by nucleofection allows stable gene expression in human neural progenitor cells. J. Neurosci. Methods 178, 15-23. doi: 10.1016/j.jneumeth.2008.11.007

Falk, J., Drinjakovic, J., Leung, K. M., Dwivedy, A., Regan, A. G., Piper, M., et al. (2007). Electroporation of cDNA/Morpholinos to targeted areas of embryonic CNS in Xenopus. BMC Dev. Biol. 7:107. doi: 10.1186/1471-213X-7-107

Falk, J., Konopacki, F. A., Zivraj, K. H., and Holt, C. E. (2014). Rab5 and Rab4 regulate axon elongation in the Xenopus visual system. J. Neurosci. 34, 373-391. doi: 10.1523/JNEUROSCI.0876-13.2014

Farkas, R. H., Nakajima, S., and Nakajima, Y. (1994). Cultured neurons infected with an HSV-1-derived vector remain electrically excitable and responsive to neurotransmitter. Neurosci. Lett. 165, 153-156. doi: 10.1016/03043940(94)90732-3

Fukuda, J., and Kurata, T. (1981). Loss of membrane excitability after herpes simplex virus infection in tissue-cultured nerve cells from adult mammals. Brain Res. 211, 235-241. doi: 10.1016/0006-8993(81)90090-1

Glatzel, M., Flechsig, E., Navarro, B., Klein, M. A., Paterna, J. C., Bueler, H., et al. (2000). Adenoviral and adeno-associated viral transfer of genes to the peripheral nervous system. Proc. Natl. Acad. Sci. U.S.A. 97, 442-447. doi: 10.1073/pnas.97.1.442

Goetze, B., Grunewald, B., Baldassa, S., and Kiebler, M. (2004). Chemically controlled formation of a DNA/calcium phosphate coprecipitate: application for transfection of mature hippocampal neurons. J. Neurobiol. 60, 517-525. doi: 10.1002/neu.20073

Gulick, J., and Robbins, J. (2009). Cell-type-specific transgenesis in the mouse. Methods Mol. Biol. 561, 91-104. doi: 10.1007/978-1-60327-019-9_6

Hitoshi, S., Kusunoki, S., Kanazawa, I., and Tsuji, S. (1999). Dorsal root ganglia neuron-specific promoter activity of the rabbit beta-galactoside alpha1,2-fucosyltransferase gene. J. Biol. Chem. 274, 389-396. doi: 10.1074/jbc. 274.1.389

Jones, J. M., Montcouquiol, M., Dabdoub, A., Woods, C., and Kelley, M. W. (2006). Inhibitors of differentiation and DNA binding (Ids) regulate Math1 and hair cell formation during the development of the organ of Corti. J. Neurosci. 26, 550-558. doi: 10.1523/JNEUROSCI.3859-05.2006

Karra, D., and Dahm, R. (2010). Transfection techniques for neuronal cells. J. Neurosci. 30, 6171-6177. doi: 10.1523/JNEUROSCI.0183-10.2010

Kawabata, I., Umeda, T., Yamamoto, K., and Okabe, S. (2004). Electroporationmediated gene transfer system applied to cultured CNS neurons. Neuroreport 15, 971-975. doi: 10.1097/00001756-200404290-00008

Ketschek, A., and Gallo, G. (2010). Nerve growth factor induces axonal filopodia through localized microdomains of phosphoinositide 3-kinase activity that drive the formation of cytoskeletal precursors to filopodia. J. Neurosci. 30, 12185-12197. doi: 10.1523/JNEUROSCI.1740-10.2010

Kirton, H. M., Pettinger, L., and Gamper, N. (2013). Transient overexpression of genes in neurons using nucleofection. Methods Mol. Biol. 998, 55-64. doi: 10.1007/978-1-62703-351-0_4

Lin, C. R., Chen, K. H., Yang, C. H., Cheng, J. T., Sheen-Chen, S. M., Wu, C. H., et al. (2010). Sonoporation-mediated gene transfer into adult rat dorsal root ganglion cells. J. Biomed. Sci. 17:44. doi: 10.1186/1423-0127-17-44

MacGillavry, H. D., Stam, F. J., Sassen, M. M., Kegel, L., Hendriks, W. T., Verhaagen, J., et al. (2009). NFIL3 and cAMP response element-binding 
protein form a transcriptional feedforward loop that controls neuronal regeneration-associated gene expression. J. Neurosci. 29, 15542-15550. doi: 10.1523/JNEUROSCI.3938-09.2009

Maehlen, J., Wallen, P., Love, A., Norrby, E., and Kristensson, K. (1991). Paramyxovirus infections alter certain functional properties in cultured sensory neurons. Brain Res. 540, 123-130. doi: 10.1016/0006-8993(91) 90498-K

Martinez, C. Y., and Hollenbeck, P. J. (2003). Transfection of primary central and peripheral nervous system neurons by electroporation. Methods Cell Biol. 71, 339-351. doi: 10.1016/S0091-679X(03)01016-1

McCall, J., Nicholson, L., Weidner, N., and Blesch, A. (2012). Optimization of adult sensory neuron electroporation to study mechanisms of neurite growth. Front. Mol. Neurosci. 5:11. doi: 10.3389/fnmol.2012.00011

Melli, G., and Hoke, A. (2009). Dorsal root ganglia sensory neuronal cultures: a tool for drug discovery for peripheral neuropathies. Exp. Opin. Drug Discov. 4, 1035-1045. doi: 10.1517/17460440903 266829

Newbern, J. M., Li, X., Shoemaker, S. E., Zhou, J., Zhong, J., Wu, Y., et al. (2011). Specific functions for ERK/MAPK signaling during PNS development. Neuron 69, 91-105. doi: 10.1016/j.neuron.2010.12.003

Ohki, E. C., Tilkins, M. L., Ciccarone, V. C., and Price, P. J. (2001). Improving the transfection efficiency of post-mitotic neurons. J. Neurosci. Methods 112, 95-99. doi: 10.1016/S0165-0270(01)00441-1

Pristera, A., Baker, M. D., and Okuse, K. (2012). Association between tetrodotoxin resistant channels and lipid rafts regulates sensory neuron excitability. PLoS ONE 7:e40079. doi: 10.1371/journal.pone.0040079

Saijilafu, E. M. H., and Zhou, F. Q. (2011). Genetic dissection of axon regeneration via in vivo electroporation of adult mouse sensory neurons. Nat. Commun. 2, 543. doi: $10.1038 /$ ncomms 1568

Shaikh, S., and Nicholson, L. F. (2006). Optimization of the Tet-On system for inducible expression of RAGE. J. Biomol. Tech. 17, 283-292.

Sharma, D. K., Brown, J. C., Choudhury, A., Peterson, T. E., Holicky, E., Marks, D. L., et al. (2004). Selective stimulation of caveolar endocytosis by glycosphingolipids and cholesterol. Mol. Biol. Cell 15, 3114-3122. doi: 10.1091/mbc.E04-03-0189

Storey, N., Latchman, D., and Bevan, S. (2002). Selective internalization of sodium channels in rat dorsal root ganglion neurons infected with herpes simplex virus1. J. Cell Biol. 158, 1251-1262. doi: 10.1083/jcb.200204010

Tonges, L., Lingor, P., Egle, R., Dietz, G. P., Fahr, A., and Bahr, M. (2006). Stearylated octaarginine and artificial virus-like particles for transfection of siRNA into primary rat neurons. RNA 12, 1431-1438. doi: 10.1261/rna.2252206

Towne, C., Pertin, M., Beggah, A. T., Aebischer, P., and Decosterd, I. (2009) Recombinant adeno-associated virus serotype 6 (rAAV2/6)-mediated gene transfer to nociceptive neurons through different routes of delivery. Mol. Pain 5:52. doi: 10.1186/1744-8069-5-52

Yu, H., Fischer, G., Jia, G., Reiser, J., Park, F., and Hogan, Q. H. (2011). Lentiviral gene transfer into the dorsal root ganglion of adult rats. Mol. Pain 7:63. doi: 10.1186/1744-8069-7-63

Conflict of Interest Statement: The authors declare that the research was conducted in the absence of any commercial or financial relationships that could be construed as a potential conflict of interest.

Received: 06 November 2014; accepted: 06 January 2015; published online: 02 February 2015.

Citation: Yu L, Reynaud F, Falk J, Spencer A, Ding Y-D, Baumlé V, Lu R, Castellani $V$, Yuan $C$ and Rudkin BB (2015) Highly efficient method for gene delivery into mouse dorsal root ganglia neurons. Front. Mol. Neurosci. 8:2. doi: 10.3389/fnmol.2015.00002 This article was submitted to the journal Frontiers in Molecular Neuroscience. Copyright (C) 2015 Yu, Reynaud, Falk, Spencer, Ding, Baumlé, Lu, Castellani, Yuan and Rudkin. This is an open-access article distributed under the terms of the Creative Commons Attribution License (CC BY). The use, distribution or reproduction in other forums is permitted, provided the original author(s) or licensor are credited and that the original publication in this journal is cited, in accordance with accepted academic practice. No use, distribution or reproduction is permitted which does not comply with these terms. 